\author{
Military Technical College \\ Kobry El-Kobbah, \\ Cairo, Egypt
}

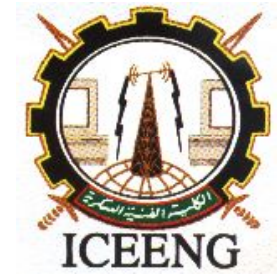

\title{
Speed Control of Micro Gas Turbine with PMSG using Evolutionary Computational Techniques
}

\author{
$10^{\text {th }}$ International Conference \\ on Electrical Engineering \\ ICEENG 2016
}

\author{
I. A. Moustafa* M. A. Moustafa Hassan** \\ * Gulf of Suez Petroleum Company (GUPCO) \\ Red Sea, Egypt \\ eng.moustafaia@gmail.com \\ **Department of Electrical Power and Machines \\ Faculty of Engineering \\ Cairo University, Giza, Egypt \\ mmustafa@eng.cu.edu.eg
}

\begin{abstract}
This paper studies speed control of Micro Gas Turbine with PD controller. The article investigate the behavior of Micro Gas turbine with PMSG under load variations using different controllers .Most of these controllers are based on Evolutionary Computational Techniques (ECT), among these Evolutionary Computational Techniques, Genetic Algorithm (GA), Particle Swarm Optimization (PSO), and Adaptive Accelerated Coefficients Particle Swarm Optimization (AACPSO). In this study, PD parameters are defined using a conventional PD controller is tuned by Ziegler-Nicholas technique. The conventional controller compared with (ECT). Simulation results show that the response of the PSO-Fuzzy like PD, AACPSO-Fuzzy like PD, and AACPSO-PD controller is effectively improved compared with other controllers. The effectiveness of the proposed scheme is confirmed via extensive study using MATLAB-Simulink software. The obtained results are promising.
\end{abstract}

Keywords: Micro Gas Turbine, PMSG, Genetic Algorithm, Speed Control, PSO algorithm

\section{Introduction}

In recent years, application of Distributed Generation (DG) sources has increased significantly. Micro Gas Turbine (MGT) is well suitable for different (DG) applications, because it can be connected in parallel to serve larger loads, and it can provide reliable power and has low emission. (DG) comes in different forms such as on - site gas or diesel fired turbines, reciprocating engines, micro turbines, small hydro induction generators, wind turbines and fuel cells [1]. Proper modeling of the MGT is needed in order to study their operation and impact on power systems. This study deals with the simulation of a Micro Gas Turbine (MGT) system comprising of a Permanent Magnet Synchronous Generator (PMSG).It is driven by a Micro Gas Turbine, suitable for stand-alone as well as grid connected operation. Micro Gas Turbines are small gas turbines which burn gaseous or liquid fuels to create high energy gas stream that turns an electrical generator [2]. There is growing interest in the application of MGTs because they can start gas turbine, suitable for stand-alone as well as grid connected operation. There is growing interest in the application of MGTs as they can start quickly and are especially useful for on-peak power supply for grid support. Generally conventional gas turbines range from 500 $\mathrm{kW}$ to more than $300 \mathrm{MW}$ [4 - 7], MTG systems range from 30 to 400 kilowatts [3]. Micro turbines are capable of burning a number of fuels at high and low pressure levels further, as 
well as their design simplicity and relatively fewer moving parts, micro turbines have the potential for simpler installation, higher reliability, reduced noise and vibration, lower maintenance requirements, lower emissions, continuous combustion and possibly lower capital costs compared to reciprocating engine [8 - 9]. There are mainly two types of micro turbine systems available, single-shaft model and two shaft model. In single shaft designs, a single expansion turbine turns both the compressor and the generator. As a result they operate at high speeds, some in excess of 100,000 rpm. Two-shaft models, on the other hand, use a turbine 
to drive the compressor on one shaft and a power turbine on a separate shaft connected to a conventional generator via a gear box which generates AC power at $60 \mathrm{~Hz}$ or $50 \mathrm{~Hz}$ [9]. The purpose of this paper is to design a controller to control the speed of the gas turbine based on ECT. The responses of ECT are compared with the conventional controller for the same turbine model. This article is organized as following: Section II gives an overview for the Integrated MTG System. Section III presents the Simulated Model. Moreover, Section IV introduces the GA. Furthermore, Section V discusses the concept of Fuzzy Logic. Meanwhile, Section VI discusses the PSO. Section VII displays the Simulation Results. Finally the Conclusion of the article is given. An appendix is given at the end of the article after an updated list of References.

\section{System Overview}

The basic components of a micro turbine generation system are the turbine, high speed generator, power electronics interfacing, and filter. Figure 1 illustrates the schematic diagram of a single-shaft micro turbine, which are more familiar in the market, based generation system. Micro turbines, like large gas turbines, operate based on the thermodynamic cycle known as the Brayton cycle [11]. In this cycle, the inlet air is compressed in a radial (or centrifugal) compressor. The compressed air is mixed with fuel in the combustor and burned. The hot combustion gas is then expanded in the turbine section, producing rotating mechanical power to drive the compressor and the electric generator, mounted on the same shaft (single-shaft) design. The microtubule produces electrical power either via high-speed generator (PMSG) turning on the single turbo-compressor shaft. In PMSG the dc field winding of the rotor is replaced by a permanent magnet [14]. This power conditioning is used to convert the high frequency $\mathrm{AC}$ power produced by the generator into usable electricity. The high frequency AC

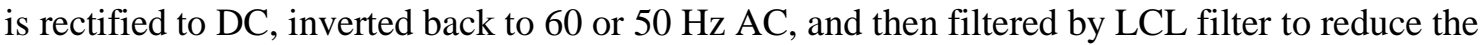
high order harmonics at grid side (load side). Micro turbines are generally equipped with controls that allow the unit to be operated in parallel or independent of the grid, and internally incorporate many of the grid and system protection features required for interconnect. The controls also allow for remote monitoring and operation [5].

$\begin{array}{ccccc}\text { High Speed } & \text { Rectifier } & \text { Inverter } & \text { Filter } & \text { Utility } \\ \text { PM } & & & \text { Network } \\ \text { Generator } & & & \end{array}$

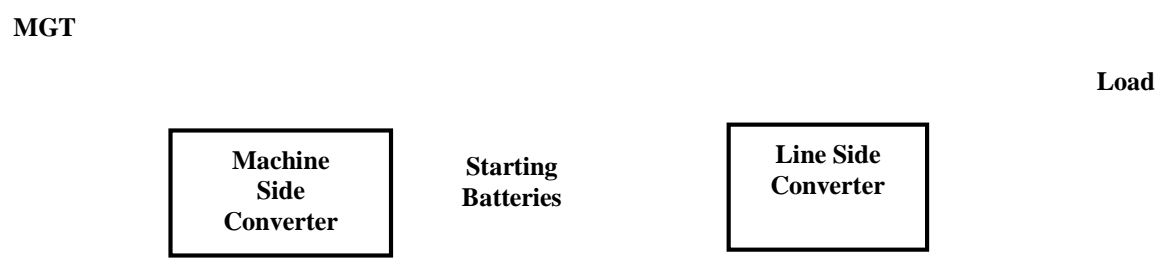

Figure 1 Integrated MTG System

\section{Mathematical Model of Micro Gas Turbine}

The micro turbine system presented in this section is based on the gas turbine model presented by Rowen [4] , the dynamic model of gas turbine and its control systems is shown in Figure 2 which was successfully adopted for micro turbine modeling by several authors [12 - 13]. The components of the single-shaft gas turbine modeled include speed control, temperature control 
and the fuel system. The three control functions of the micro turbine are: speed control this controller removes the start controller out of service during the speeds close to the nominal speed, it is in charge of increasing the turbine speed at the end of starting stage and accurately regulating the speed before the synchronization unit and close the generator breaker, and is in change load to adjust speed at nominal value, acceleration control is used primarily during turbine startup to limit the rate of the rotor acceleration prior to reaching operating speed, and the temperature controller is responsible to prevent the turbine over loading if the temperature exceeds the maximum turbine's tolerable temperature threshold. The output signals of the above-mentioned controllers enter to a MIN gate block, as displayed at figure 2, it is determined which controller is active and controls the turbine operation. In the Rowen model [4], the Low Value Selector (LVS) system inputs are three signals obtained from speed, temperature, and acceleration control systems. Two functions exist in model structure. The first one, $f_{1}$, calculates the exhaust temperature in terms of the turbine speed, $N$, and the fuel flow, $W_{f}$. The second one is, $f_{z}$, which calculates the turbine torque in terms of $N$ and $W_{f}$.

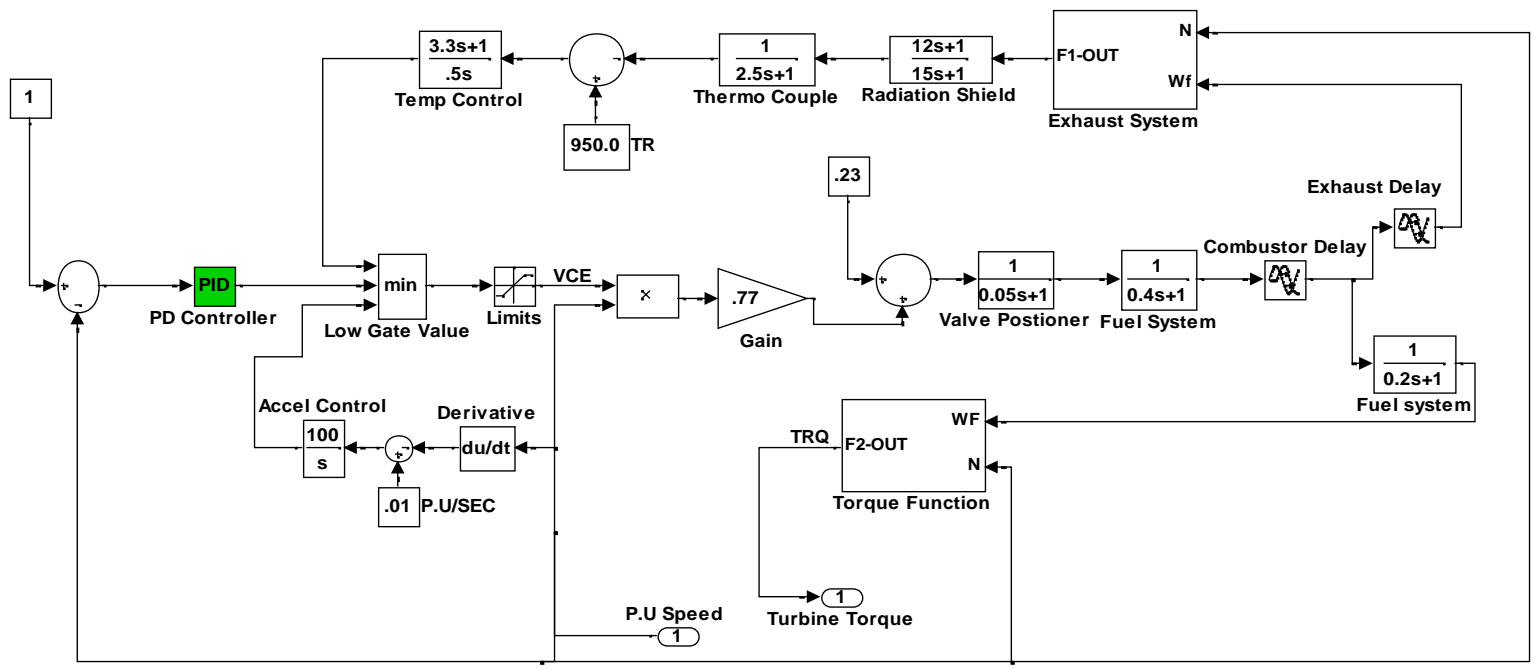

Figure 2 Simulink Model of the Micro-Turbine

\section{Genetic Algorithm}

The Genetic Algorithm (GA) is an optimization and search technique based on the principles of genetics and natural selection. The GA allows a population composed of many individuals to evolve under specified selection rules to a state that maximizes the "fitness" (i.e., minimizes the cost function); many versions of evolutionary programming have been tried with varying degrees of success [15]. The basic operating principles of GAs are based on the principles of natural evolution. This algorithm works with a set of population of candidate solution represented as strings. The initial population consists of randomly generated parents. In every iteration of the algorithm, fitness of each individual in current population is computed. The population is then transformed in stages to yield a new current population for next iteration. The transformation is usually done in three stages by simply applying the following genetic operators: (1) selection, (2) crossover, and (3) mutation. In the first stage selection operator is applied as many times as there are individuals in the population. In this stage every individual is replicated with a probability proportional to its relative fitness in the population. In the next stage, individuals are chosen and combined to produce two new individuals. The combination is done by choosing at random a cutting point at which each of parents is divided into two parts; these are exchanged to form the two offspring which replace their parents in the population. In the final stage, as displayed in Figure 3, the mutation operator changes the values in a randomly chosen location on an individual. 


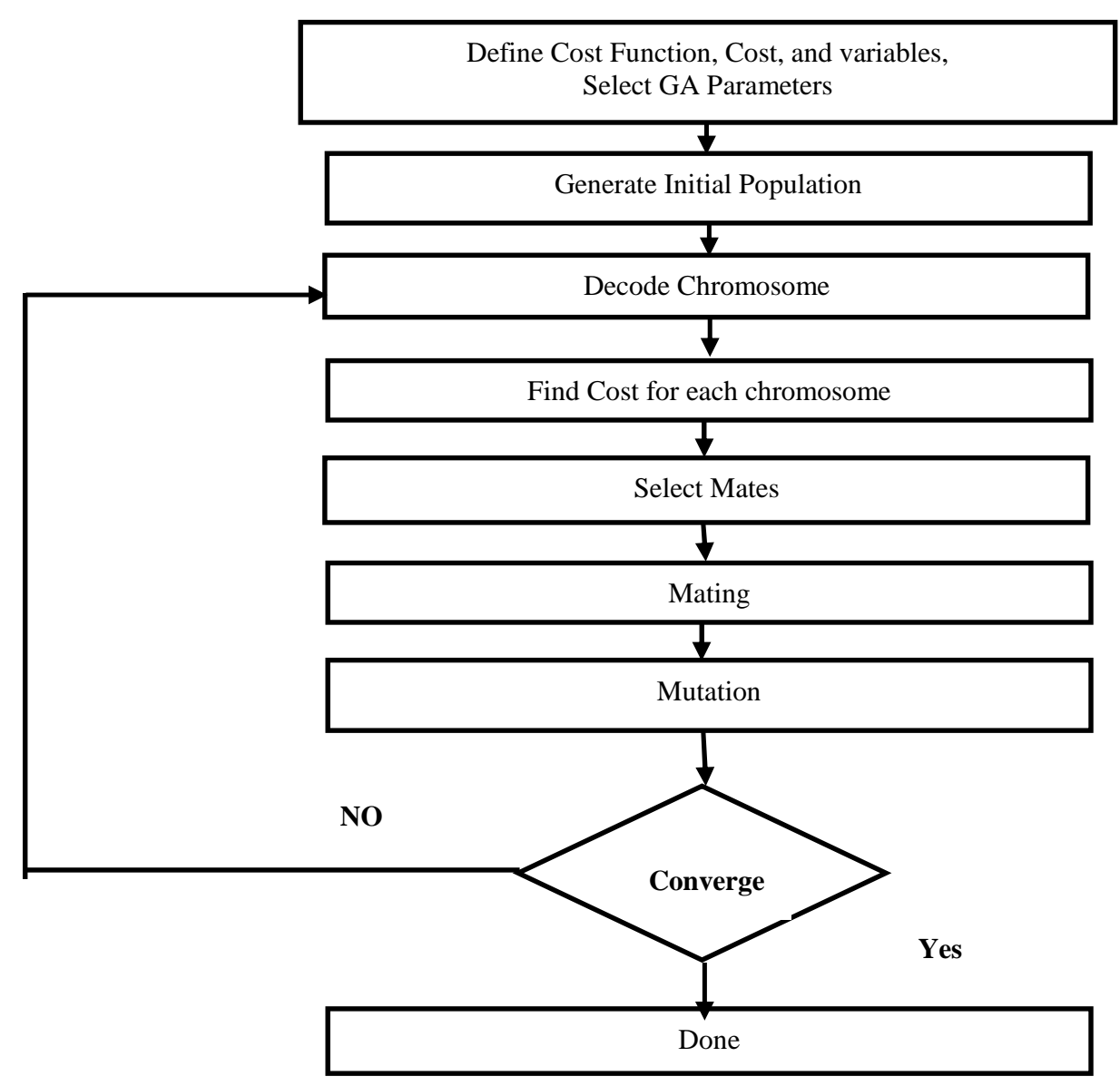

Figure 3 Flow Chart of GA

The algorithm terminates after a fixed number of iterations and the best individual generated during the run is taken as the solution, as explained in [15].

\section{Fuzzy Logic}

Fuzzy logic (FL) was first proposed by Lotfi A. Zadeh (1965) [16] and is based on the concept of fuzzy sets. Fuzzy set theory provides a means for representing uncertainty In general, probability theory is the primary tool for analyzing uncertainty, and assumes that the uncertainty is a random process. However, not all uncertainty is random, and fuzzy set theory is used to model the kind of uncertainty associated with imprecision, vagueness and lack of information. On the other hand, fuzzy systems are multi input single output mappings from a real valued vector to a real valued scalar [16] The basic structure of a fuzzy logic controller is illustrated in Figure 4, as presented in [18] A Fuzzy Logic Controller (FLC) commonly consists of four sections including: Fuzzification, Inference Engine, Rule Bases, and Defuzzification. A rule base is made up of series of IF-THEN rules corresponding to the fuzzy inputs and leading to the fuzzy outputs. The rules can be developed using knowledge from experts or operators in the field, as well as historical experience.

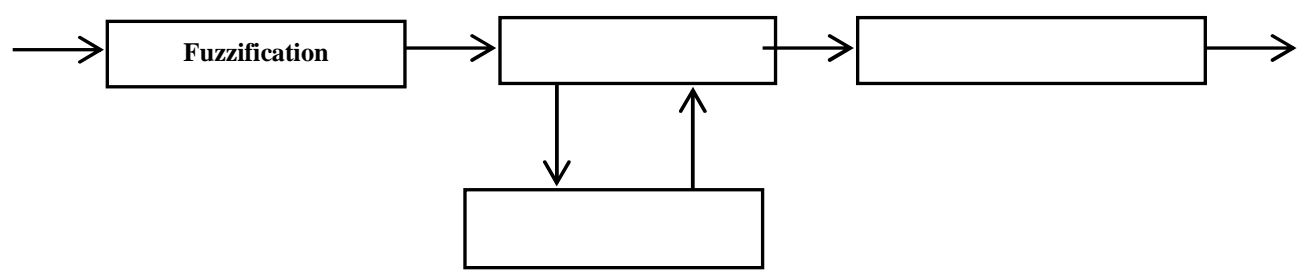

Figure 4 Fuzzy Logic Controller Structure 
To design the fuzzy controller some variables which can represent the dynamic performance of the system should be chosen to be fed as the inputs [18]. In this paper the fuzzy logic controller has two inputs and one output. The inputs are turbine speed deviation (e) and its derivative (de) and the output is the change in controller position. The number of linguistic terms for each linguistic variable is selected as seven (Negative Big=NB, Negative Mean=NM, Negative Small=NS, Positive Small=PS, Positive Mean=PM, Positive Big=PB). The inference mechanism is based on Mamdani technique. In this design, the minimum is applied for data AND operator, maximum for OR operator, minimum for implication operator maximum for aggregation operator, and finally centroid technique for Defuzzification. The membership functions for inputs variations are Gaussian and they are considered triangular for the controller output variations. The membership function of inputs and the output variations are shown in Figure 5 and Figure 6, respectively. The rule table for speed controller is shown in Table 1.

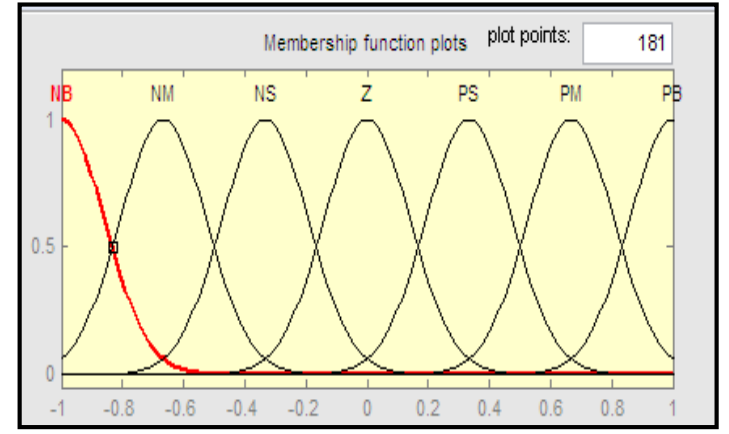

Figure 5 Membership Functions for Input

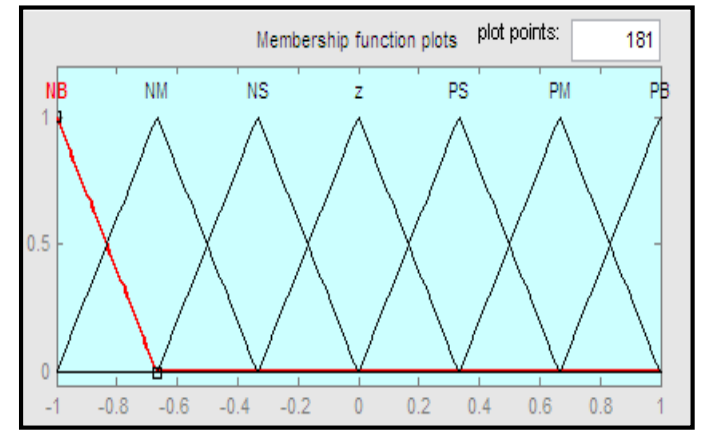

Figure 6 Membership Functions for Output

Table 1 Control Outputs (49 Rules)

\begin{tabular}{|c|c|c|c|c|c|c|c|c|}
\hline & \multicolumn{8}{|c|}{$\begin{array}{l}\text { de } \\
\end{array}$} \\
\hline \multirow{8}{*}{ e } & & 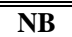 & 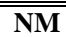 & NS & $\overline{\overline{Z Z}}$ & 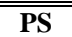 & $\overline{P \text { PM }}$ & $\overline{\overline{P B}}$ \\
\hline & NB & NB & NB & NB & NM & NM & NS & $\mathbf{Z}$ \\
\hline & "NM & NB & NB & NM & NM & NS & $\mathbf{Z}$ & $\overline{\overline{P S}}$ \\
\hline & 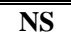 & $\overline{\mathrm{NB}}$ & 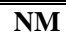 & NS & 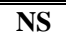 & $\overline{\bar{Z}}$ & 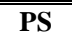 & $\overline{\overline{P M}}$ \\
\hline & $\overline{Z Z}$ & NM & NM & NS & $\overline{Z Z}$ & PS & PM & PM \\
\hline & PS & NM & $\overline{\mathrm{NS}}$ & $\overline{Z Z}$ & PS & $\begin{array}{l}\text { PS } \\
\end{array}$ & PM & PB \\
\hline & PM & NS & $\bar{Z}$ & PS & PM & PM & PB & PB \\
\hline & PB & $\mathrm{Z}$ & PS & PM & PM & PB & PB & PB \\
\hline
\end{tabular}

\section{Particle Swarm Optimization}

Particle Swarm Optimization (PSO) is one of the most powerful stochastic optimization techniques developed by Eberhart and Kennedy in 1995 [19]. It has recently attracted more attention due to its rapid convergence and algorithmic accuracy compared to other optimization methods. PSO is inspired by social behavior of bird flocking or fish schooling and shares many similarities with evolutionary computation techniques such as GA [20].

\section{a) PSO:}

Particle swarm optimization (PSO) is based on the swarm behavior such as fish and bird schooling in nature. Since then, PSO has generated much wider interests, and forms an exciting, ever-expanding research subject, called swarm intelligence. PSO has been applied to almost every area in optimization, computational intelligence, and design/ scheduling applications. There are at least two dozens of PSO variants, and hybrid algorithms by combining PSO with other existing algorithms are also increasingly popular. The principle of 
PSO is to simulate a collective behavior used to show the motion of birds and fish. PSO has simulated the birds' motion along two directions. The position of each individual (representative) is represented by $\mathrm{x} y$ vectors and $\mathbf{v}_{\mathbf{x}}$ (velocity on $\mathrm{x}$-axis) and $\mathbf{v}_{\mathbf{y}}$ (velocity on $\mathrm{y}$-axis) express the velocity. Although in PSO, each member has an adaptive speed (location change) due to which moves in search space, each one has a memory, in other words, it remembers the best position it has reached in the search space. Therefore, each member moves on two directions. 1- Towards the best position they have met, 2- Towards the best position the best member has met in neighborhood. According to the issues mentioned above, the position of each member is determined via its own speed and position. The velocity and position of each particle is modified according to Equation 1 and Equation 2, respectively [21]:

$v_{i}^{k+1}=w v_{i}^{k+1}+c_{1}$ rand $_{1} \times\left(\right.$ pbest $\left._{i}-s_{i}^{k}\right)+c_{2}$ rand $_{2} \times\left(\right.$ gbest $\left._{i}-s_{i}^{k}\right)$

(1)

$$
s_{i}^{k+1}=v_{i}^{k+1}+s_{i}^{k}
$$

Where,

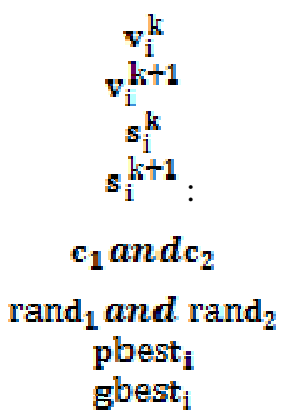

Current velocity of particle $i$ at iteration $\mathrm{k}$

New velocity of particle $i$ at next iteration $k+1$

Current position of particle $\mathrm{i}$ at iteration $\mathrm{k}$

New position of particle $i$ at next iteration $k+1$

Adjustable cognitive and social acceleration constants

random number between 0 and 1

Personal best of particle $\mathrm{i}$

Global best of the population

The algorithmic steps involved in PSO algorithm are displayed in Figure 7 and discussed as follows:

1. Initialize the population - positions and velocities

2. Evaluate the desired optimization fitness function of the individual particle (pbest)

3. Keep track of the individuals' highest fitness (gbest )

4. Modify velocities based on pbest and gbest position

5. Update the particles velocities and positions according to Equation 1 and Equation 2.

6. Repeat steps 3-6 until the stopping criterion of maximum generations is met.

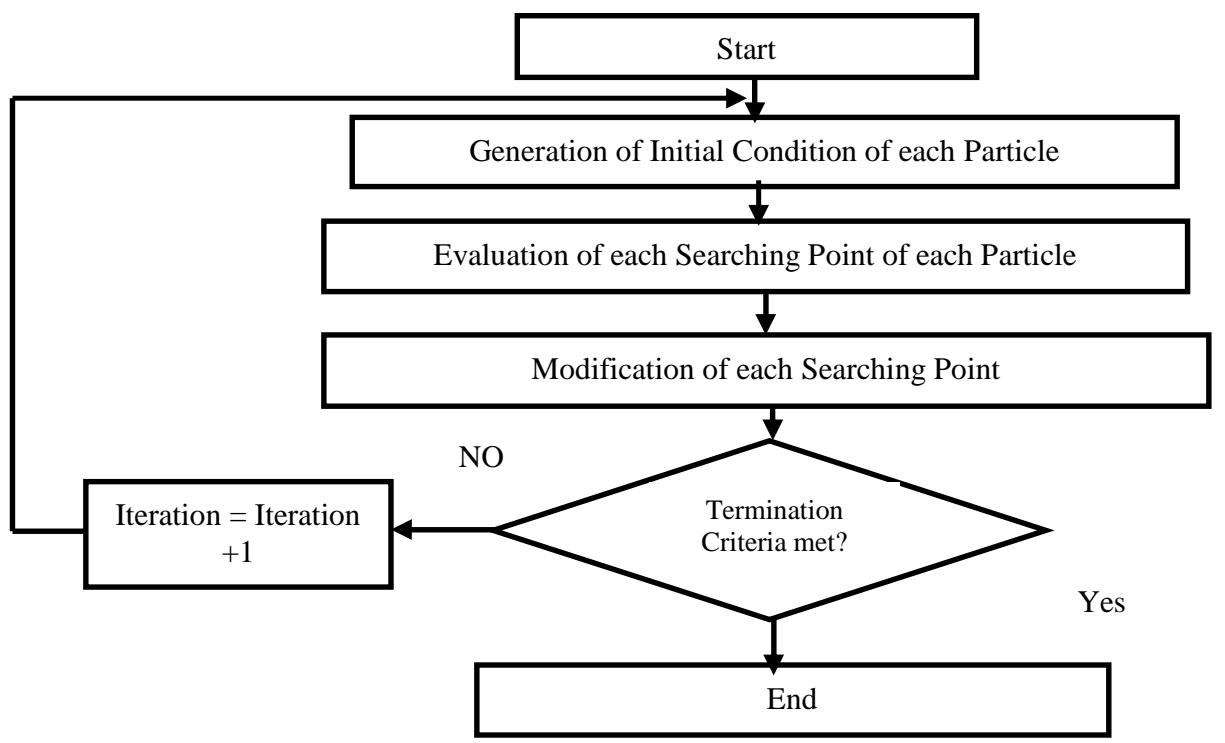


Figure 7 Flow Chart of PSO 


\section{b) AACPSO:}

The standard particle swarm optimization uses both the current global best gbest $_{\mathbf{i}}$ and the individual best pbest. The reason of using the individual best is primarily to increase the diversity in the quality solutions; however, this diversity can be simulated using some randomness. Subsequently, there is no compelling reason for using the individual best, unless the optimization problem of interest is highly nonlinear and multimodal. A simplified version which could accelerate the convergence of the algorithm is to use the global best only. Thus, in the Adaptive Accelerated Coefficients PSO (AACPSO) [20], the velocity vector is generated by a simpler formula Equation 1 further improvement to the PSO is Adaptive Accelerated Coefficients PSO (AACPSO) to reduce the randomness as iterations proceed. This means that we can use a monotonically decreasing function such as:

$$
\begin{aligned}
& c_{1}=c_{01} e^{-k_{i} t \alpha_{c}} \\
& c_{2}=c_{02} e^{-k_{c} t \alpha_{c}} \\
& w=w_{0} e^{-t \alpha_{w}} \\
& \alpha_{c}=\frac{1}{t_{m a x}} \cdot I n\left(\frac{c_{02}}{c_{01}}\right) \\
& \boldsymbol{k}_{c}=\frac{F_{m}-\text { Gbest }}{F_{m}}
\end{aligned}
$$

Where $w, c_{1}$ and $c_{1}$ are the inertia weight factor and acceleration coefficients respectively at iteration $\mathrm{t}, \ln$ is the neperian logarithm. $\alpha_{w}$ is determined with respect to initial and final values of $w$ with the same manner as $\alpha_{\sigma} . k_{\sigma}$ is calculated based on the fitness value of Gbest and Pbest at iteration t. $w_{0}, c_{01}$ and $c_{0 z}$ initial values of inertia weight factor and acceleration coefficients respectively. $F_{m}$ is the mean value of the best positions related to all particles at iteration $\mathrm{t}$, as illustrated at [22].

\section{Simulation and Discussions of Results}

The performance of the controller designed for operating condition is evaluated. Seven controllers, ZN, GA-PD, evaluated. Seven controllers, ZN, GA-PD, GA-Fuzzy like PD, PSOPD, PSO-Fuzzy like PD, AACPSO-PD,AACPSO-Fuzzy like PD, are designed for gas turbine model and the results are compared in order to evaluate the performance of the controllers. To investigate the performance of the designed controllers under different operating conditions, the operating condition of the system has been changed. The simulation parameters are given in Appendix A. Figure 8 shows the developed model of the MGT system with external DC source in MATLAB / SIMULINK using SIMPOWER toolbox. The operation of PMSG in generating or motoring mode is decided by the sign of the input mechanical torque. During start-up the PMSG operates as a motor to bring the turbine speed of 7000 radian /sec. In this case, power flows from the DC source to MGT system [23]. The Micro turbine reaches the set value of speed in $0.4 \mathrm{sec}$. To ensure the operating condition, the speed regulator provides the reference value for the speed. In this mode of operation of MGT system, the machine side converter acts as inverter. At $\mathrm{t}=0.4 \mathrm{sec}$, the sign of the PMSG input torque is changed to operate it in generating mode. At $\mathrm{t}=0.4 \mathrm{sec}$, the reference speed is set to the recalculated value of 10053 radian /sec, the DC source will removed from the system at $\mathrm{t}=1.7 \mathrm{sec}$. After that, the MGT system will supply the power to the load continuously. During the operation, the DC link voltage must be maintained constant by the line side converter. In 
this model, machine side and line side converter controllers are very important as machine side controller maintains the PMSG voltage level and the micro-turbine ignition speed level. If ignition speed is not maintained, the PMSG will be shutdown. The line side converter is maintaining the constant DC voltage level and the load side voltage level. It is observed that the machine side and the line side converter controllers are working properly. So, the microturbine maintains the ignition speed and the PMSG runs as a generator. The MGT system delivering the rated active power to the load continuously and the load side voltage and current wave forms are sinusoidal.

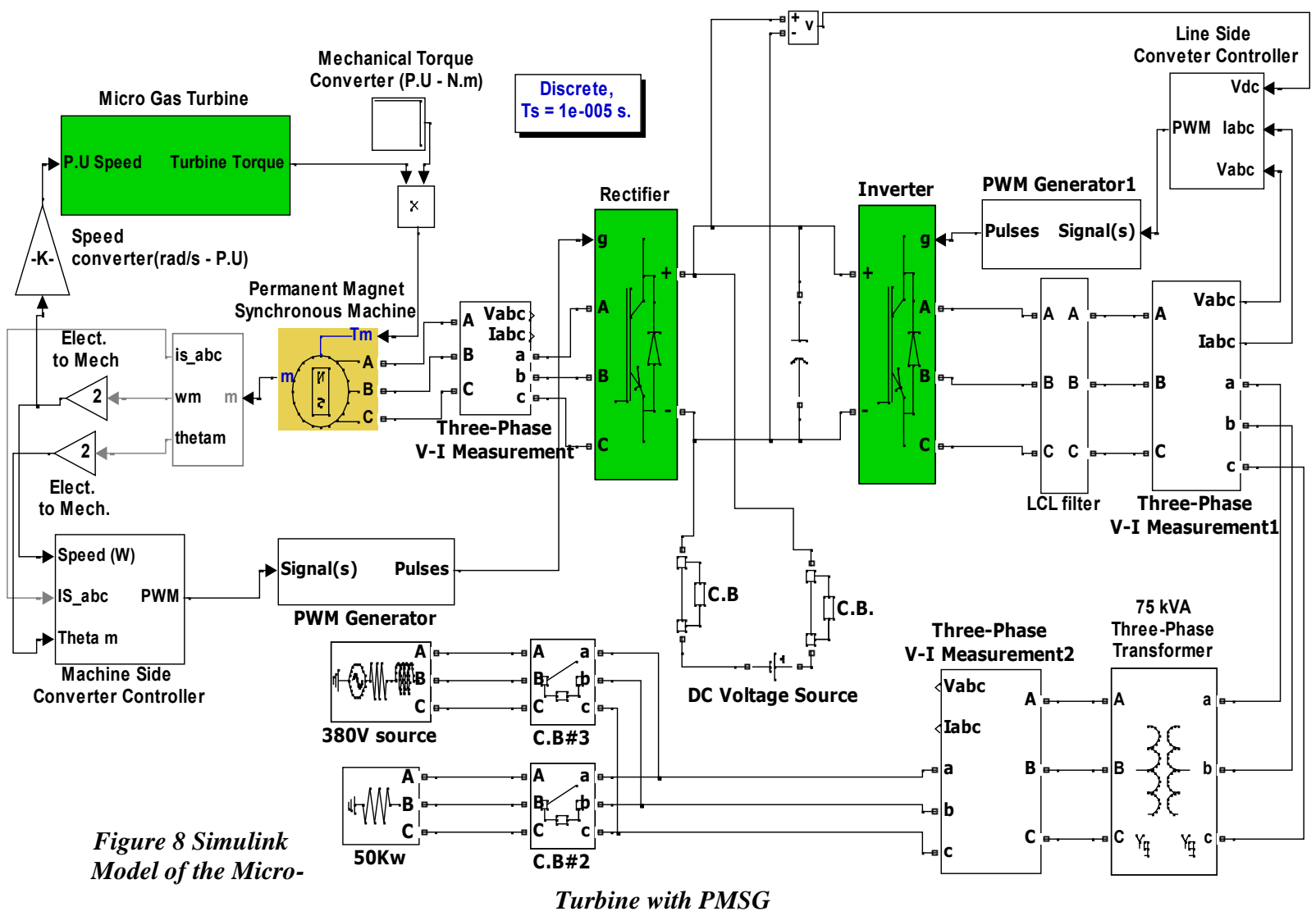

PID and PI controllers are not chosen due to unstable speed response obtained from simulation results, so that PD controller which will be used at this paper
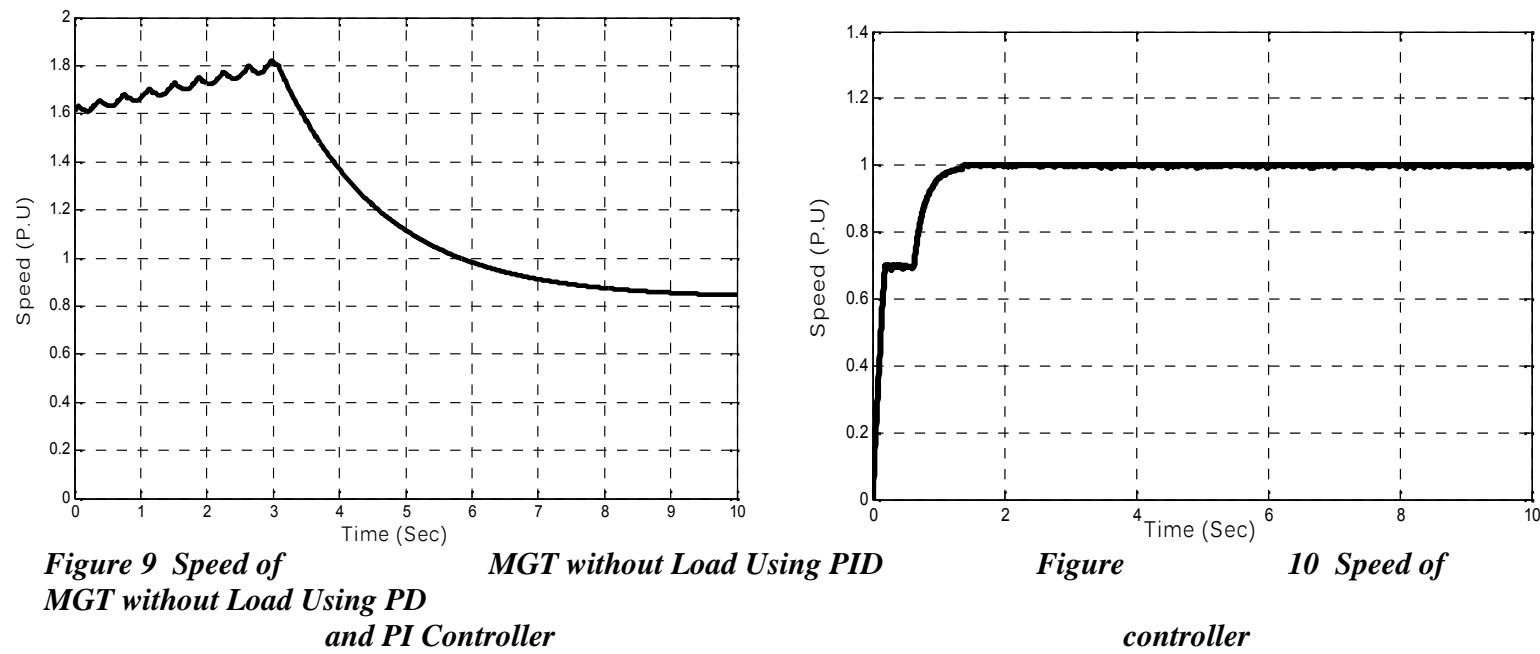

and PI Controller

controller 
The load variations curve is shown in Figure 11, the load is applied (50kW) at $3 \mathrm{Sec}$ at island mode, and in the grid mode the load is applied $(50 \mathrm{~kW})$ at $1.8 \mathrm{Sec}$ and utility network at $3 \mathrm{Sec}$ 


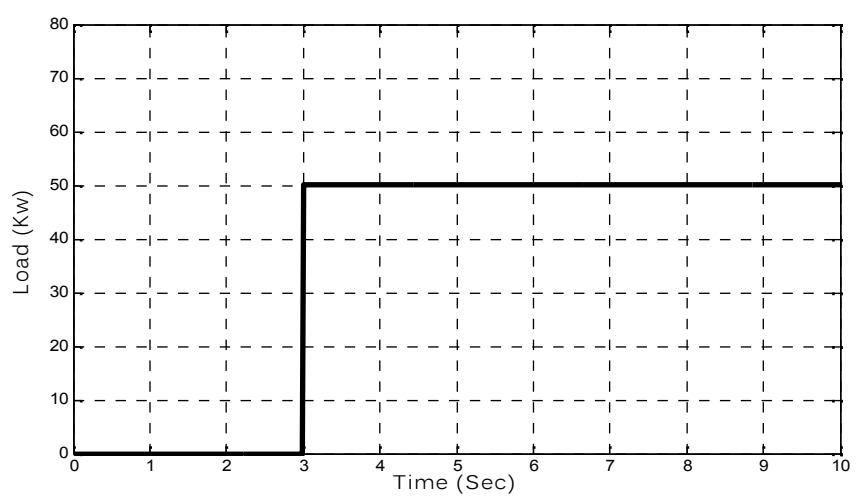

Figure 11 Load Curve

The load voltage and current waveform are displayed in Figure 12, and Figure 13

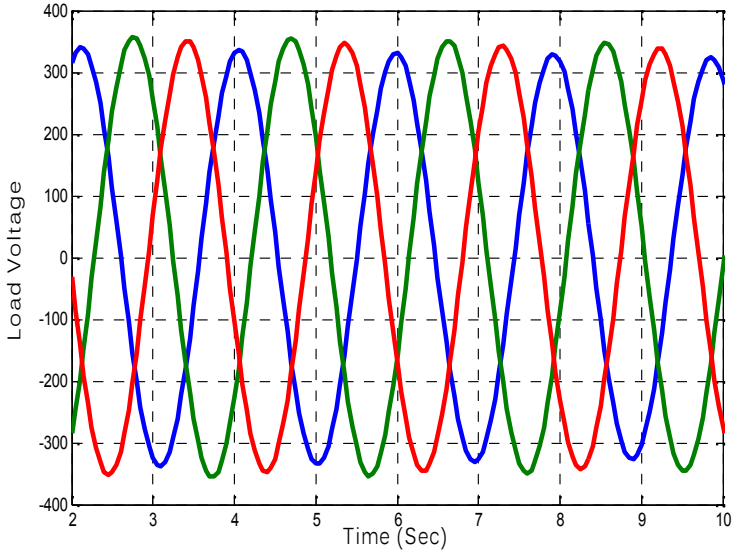

Figure 12 Load Voltage

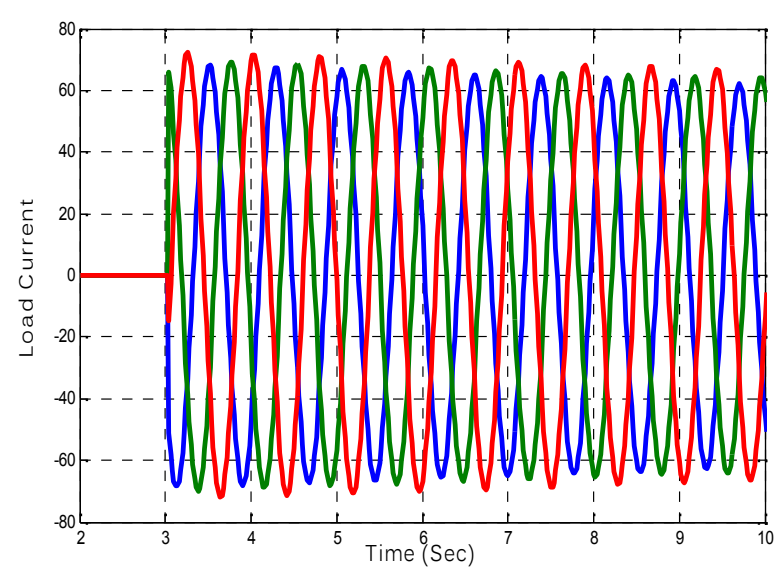

Figure 13 Load Current

From the operation of the seven controllers in power controlling against the load variations shows that the response curve with PSO-Fuzzy like PD under IAE performance index and AACPSO-Fuzzy like PD under ITAE performance index has the best values of over shoot $(0.01 \%)$ and settling time $(1 \mathrm{Sec})$, after them comes GA-Fuzzy like PD under ITAE performance index $(0.23 \%)$ and $(1.5 \mathrm{Sec})$ in the case of island mode. In grid mode AACPSOPD under IAE performance index comes in the first stage with over shoot $(0.01 \%)$ and settling time (1Sec) and then GA-PD under IAE performance index with over shoot $(0.4 \%)$ and settling time $(1 \mathrm{Sec})$. Based on all techniques disused on this proposal Table 2 illustrates the Comparison of Results for speed controller of MGT.

Table 2

Comparison between Proposed Tuning Methods at Island and Grid Mode

\begin{tabular}{|c|c|c|c|c|}
\hline \multirow[b]{2}{*}{ Tuning Method } & \multicolumn{2}{|c|}{ Island Mode } & \multicolumn{2}{|c|}{ Grid Mode } \\
\hline & $\begin{array}{l}\text { Over } \\
\text { Shoot }\end{array}$ & $\begin{array}{c}\text { Settling } \\
\text { Time } \\
\text { (Sec) } \\
\end{array}$ & $\begin{array}{l}\text { Over } \\
\text { Shoot }\end{array}$ & $\begin{array}{l}\text { Settling } \\
\text { Time } \\
\text { (Sec) }\end{array}$ \\
\hline ZN & $0.3 \%$ & 3 & $0.4 \%$ & 2 \\
\hline GA-PD & $0.2 \%$ & 1 & $0.4 \%$ & 1 \\
\hline $\begin{array}{c}\text { GA-Fuzzy like } \\
\text { PD }\end{array}$ & $0.23 \%$ & 1.5 & $0.4 \%$ & 2 \\
\hline PSO- PD & $0.2 \%$ & $2 S$ & $0.4 \%$ & 2 \\
\hline $\begin{array}{c}\text { PSO-Fuzzy like } \\
\text { PD } \\
\end{array}$ & $0.01 \%$ & 1 & $0.4 \%$ & 2 \\
\hline AACPSO- PD & $0.3 \%$ & 1 & $0.01 \%$ & 1 \\
\hline $\begin{array}{c}\text { AACPSO-Fuzzy } \\
\text { like PD }\end{array}$ & $0.01 \%$ & 1 & $0.4 \%$ & 2 \\
\hline
\end{tabular}


Figure 14 to Figure 15 display transient speed response under different controllers after applying the load at $3 \mathrm{sec}$ and utility network.

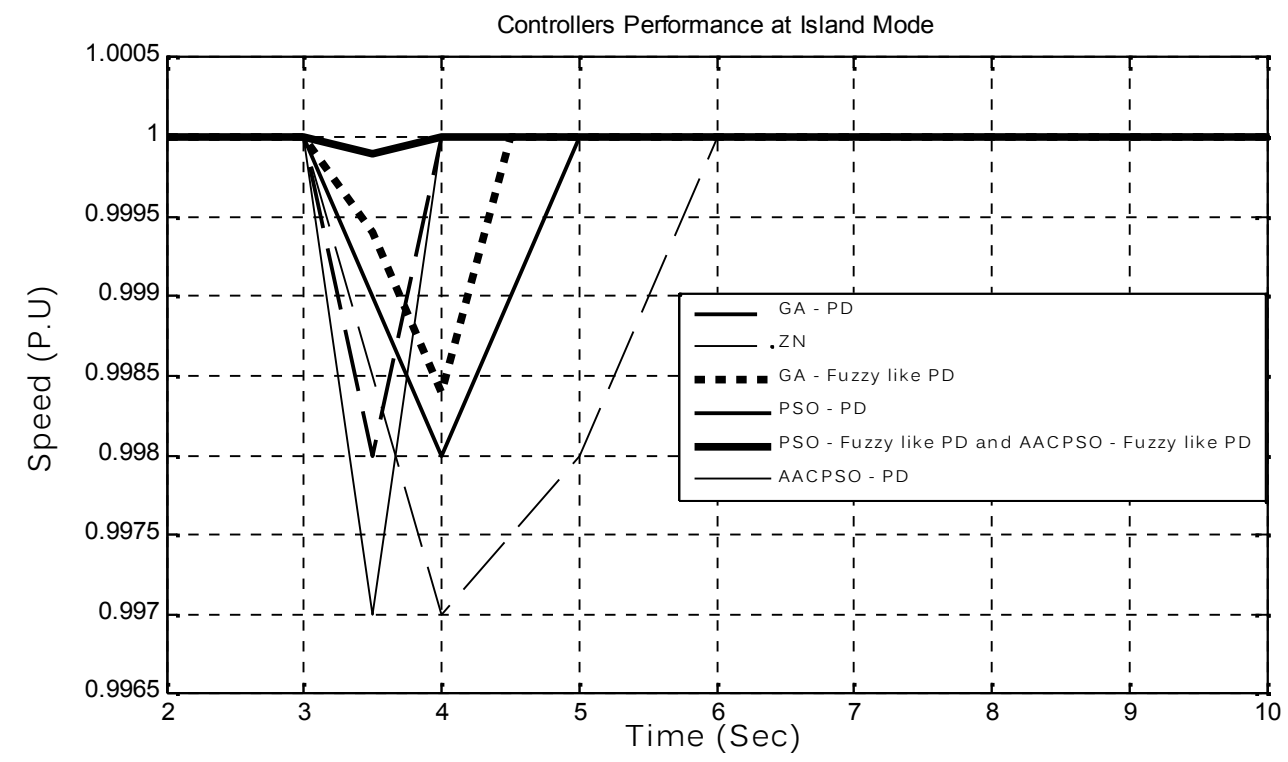

Figure 14 Speed Response of MGT at Island Mode

Controllers Performance at Grid Mode

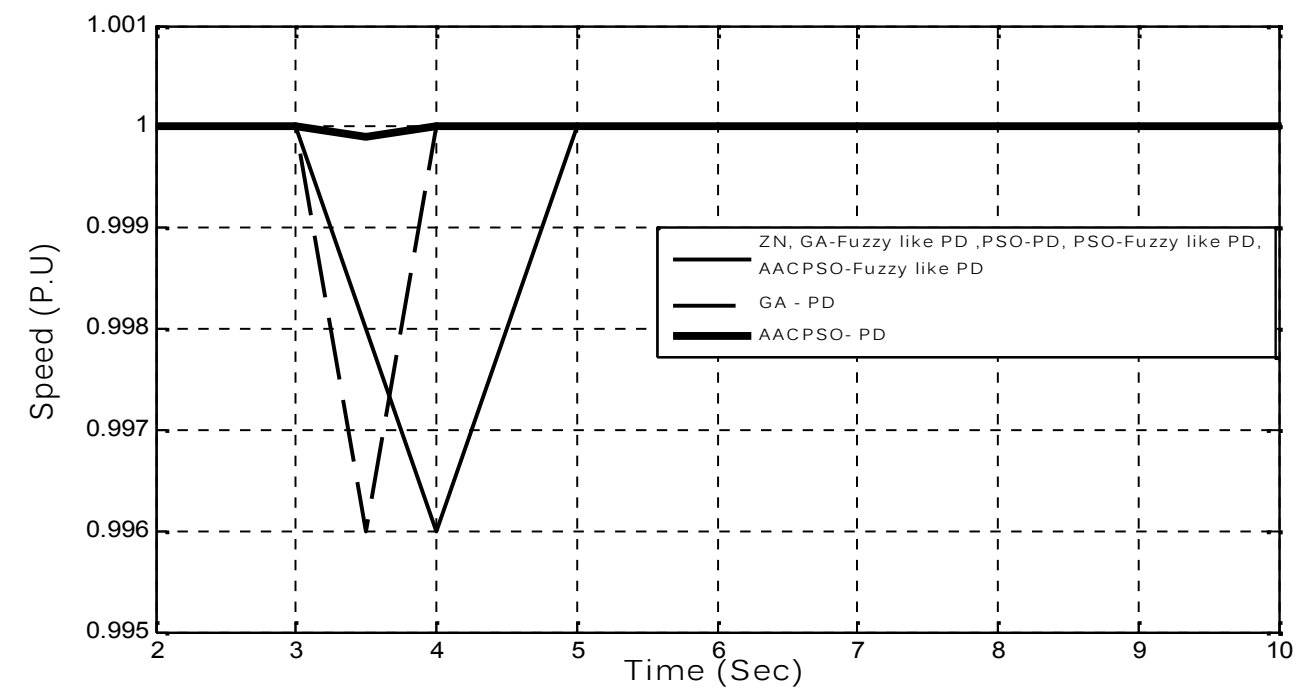

Figure 15 Speed Response of MGT at Grid Mode

It's clear from the above results that that the PSO-Fuzzy like PD , and AACPSO-Fuzzy like PD controllers have a considerable advantage in compare with other controller in speed control at island mode $\left(\mathrm{O} . \mathrm{S}=0.01 \%, \mathbf{T}_{5}=1 \mathrm{Sec}\right)$. In the grid mode the AACPSO- PD controller has a considerable advantage in compare with other controllers in speed control $\left(\mathrm{O} . \mathrm{S}=0.01 \%, \mathbf{T}_{s}=1 \mathrm{Sec}\right)$. While PSO and AACPSO are more supporter than GA and ZN.

\section{Conclusion}

In this proposed study, the ECT based PD have been investigated for speed control of a Micro Gas Turbine. For this purpose, which PSO is more adaptive tuning mechanism for the PD controller parameters is obtained . It has been shown that the proposed control algorithm is effective and provides significant improvement in system performance. Therefore, the proposed PSO and AACPSO techniques are recommended to generate good quality and 
reliable electric energy. In addition, the proposed controller is very simple and easy to implement since it does not require many information about system parameters. The obtained results are promising.

\section{References}

[1] Y. Zhu, and K. Tomsovic, "Optimal distribution power flow for systems with distributed energy resources," Electrical Power and Energy Systems, Vol. 29, pp. 260-267, 2007.

[2] Francisco Jurado and Jose Ramon Saenz, "Adaptive control of a fuel cell-micro turbine hybrid power plant," IEEE Transactions on Energy Conversion, Vol. 18, No.2, pp. 342-347, June 2003.

[3] Anne-Marie Borbely and Jan F. Kreider, Distributed generation-The Power Paradigm for the New Millennium, CRC Press, 2001.

[4] W. I. Rowen, "Simplified mathematical representations of heavy duty gas turbines", Journal of Engineering for Power, Transactions ASME, Vol. 105, No. 4, pp. 865-869, Oct, 1983.

[5] Energy and Environmental Analysis (an ICF International Company) 1655 North Fort Myer Drive Suite 600 Arlington, Virginia 22209, December 2008.

[6] L. M. Hajagos and G. R. Berube, "Utility experience with gas turbine testing and modeling," in Proc. IEEE PES Winter Meeting, Vol. 2, 2001, pp. 671-677 Jan. / Feb. 2001, Columbus, OH.

[7] Working Group on Prime Mover and Energy Supply Models for System Dynamic Performance Studies, "Dynamic models for combined cycle plants in power system studies," IEEE Transactions on Power Systems, Vol. 9, No. 3, pp. 1698-1708, August 1994.

[8] Anders Malmquist, "Analysis of a gas turbine driven hybrid drive system for heavy vehicles," Ph.D. dissertation, School of Electrical Engineering and Information Technology, KTH, Stockholm, Sweden, 1999.

[9] Amer Al-Hinai, Ali Feliachi., "Dynamic Model of a micro turbine used as a distributed Generator," in Proc. 341 Southeastern Symposium on system Theory, Huntsville, pp.209-213, Alabama, March 2002.

[10] Y. Zhu and K. Tomsovic, "Development of models for analyzing the load-following performance of micro turbines and fuel cells," Journal of Electric Power Systems Research, Vol. 62, pp. 1- 11, 2002.

[11] Larry Goldstein, Bruce Hedman, Dave Knowles, Steven I. Freedman, Richard Woods and Tom Schweizer., ";Gas-fired distributed energy resource technology characterizations," National Renewable Energy Laboratory, NREL/TP-620-34783, Nov. 2003.

[12] F. Jurado and A. Cano, "Use of ARX algorithms for modeling micro turbines on the distribution feeder," IEE Proceedings: Generation Transmission and Distribution, Vol. 151, No. 2, pp. 232-238, Mar. 2004.

[13] L. N. Hannet and Afzal Khan., "Combustion turbine dynamic model validation from tests," IEEE Transactions on Power Systems, Vol. 8, No. 1, pp. 152-158, Feb. 1993.

[14] Bimal K.Bose, Modern Power Electronics and AC Drives, Pearson Education, 2003.

[15] Randy L. Haupt Sue Ellen Haupt Practical Genetic Algorithms - Second Edition [Book]. Hoboken, New Jersey : A John Wiley \& Sons, Inc., Publication, 2004.

[16] L.A.Zadah. "Fuzzy Sets Information Control”, 338-353, (1965).

[17] Wang, L.-X. A Course In Fuzzy Systems And Control. Hong Kong: Bernard Goodwin - Prentice Hall PTR, (2004)

[18] F. Jurado, M. Ortega, A. Cano and J Carpio, "Neuro-fuzzy controller for gas turbine in biomass-based electric power plant", Electric Power Systems Research, Vol. 60, No. 3, (2002).

[19] J. Kennedy, R. C. Eberhart, Swarm intelligence, Academic Press, 2001.10

[20] A. B. M. Nasiruzzaman and M. G. Rabbani,, " Implementation of Genetic Algorithm and Fuzzy Logic in Economic Dispatch Problem", 5th International Conference on Electrical and Computer Engineering ICECE, pp. 360-365, Dhaka, Bangladesh, IEEE Conference Publication, 20-22 December 2008.

[21] Kennedy and R. Eberhart, "Particle swarm optimization", Proc. IEEE Int. Conf. Neural Networks, (1995) Australia.

[22] Salhi Ahmed, Bouktir Tarek and Naimi Djemai, "Economic Dispatch Resolution using Adaptive Acceleration Coefficients based PSO considering Generator Constraints, " Proc. IEEE Int. Conf. CG DIT, (2013)

[23] S. Morimoto, M. Sanada and Y. Takeda, 'Wide speed operation of interior permanent magnet synchronous motors with high performance current regulator,' IEEE Trans. Industrial Applications, vol. 30, pp. 920-926, July / Aug. 1994. 


\section{Appendix A}

The simulation parameters are expressed in the following Table.

\begin{tabular}{|l||l||}
\hline PMSG Parameter & $\begin{array}{l}400 \mathrm{~V}, 50 \mathrm{KW}, 1.6 \mathrm{KHZ}, 96000 \mathrm{rpm}, \mathrm{R}, \mathrm{z}=.25, \mathrm{~L}_{\mathrm{d}}=\mathrm{L}_{\mathrm{g}}=.0006875 \mathrm{H}, \\
\text { 2poles, rotor Inertia }=.0008 \mathrm{Kg} \cdot \mathrm{m} 2, \text { stator flux linkage }=.0534 \mathrm{~Wb}\end{array}$ \\
\hline \hline Micro Gas Turbine Parameters & $\begin{array}{l}\text { Manfr.: Capstone, Model:C60,60KW,96000rpm, single shaft with } \\
\text { 2pole PMG }\end{array}$ \\
\hline \hline Grid Parameters & $380 \mathrm{~V}, \quad \mathrm{R}_{\mathbf{z}}=.4, \mathrm{~L}_{\mathrm{z}}=2 \mathrm{e}-3 \mathrm{H}$ \\
\hline \hline Switching frequency & $\begin{array}{l}\text { Machine side converter }=20 \mathrm{KHZ} \\
\text { Line side converter }=2 \mathrm{KHZ}\end{array}$ \\
\hline \hline Filter Parameters & $\mathrm{L}_{1}=2 \mathrm{e}-3 \mathrm{H}, \mathrm{L}_{2}=1 \mathrm{e}-3 \mathrm{H}, \mathrm{C}(\mathrm{var})=3.5 \mathrm{Kvar}$ \\
\hline \hline DC link capacitance & $500 \mu \mathrm{F}$ \\
\hline \hline PI controllers sampling time & $100 \mu \mathrm{Sec}$ \\
\hline
\end{tabular}

The values of the GA parameters used in the simulation are displayed in the following Table

\begin{tabular}{|c||c|}
\hline Algorithm type & Continues \\
\hline Population size & 100 \\
\hline \hline Elite Count & 30 \\
\hline \hline Number of Generations & 10 \\
\hline \hline Selection method & 'Tournament' \\
\hline \hline Crossover type & 'Scattered crossover' \\
\hline \hline Crossover probability & 0.8 \\
\hline \hline Mutation type & 'Uniform mutation' \\
\hline \hline Mutation rate & .01 \\
\hline \hline
\end{tabular}

The values of the PSO parameters used in the simulation are displayed in the following Table

\begin{tabular}{|c|c|c|}
\hline \multirow{4}{*}{$\begin{array}{c}\text { Island } \\
\& \\
\text { Grid } \\
\text { mode }\end{array}$} & $\begin{array}{l}\text { Performance } \\
\text { Index }\end{array}$ & PSO Parameters \\
\hline & IAE & $\begin{array}{c}\mathrm{N}=2, \mathrm{n}=3 \\
\mathrm{C} 1=\mathrm{C} 2=0.12 \\
, \mathrm{w}=0.9\end{array}$ \\
\hline & ISE & $\begin{array}{c}\mathrm{N}=2, \mathrm{n}=3, \mathrm{C} 1=1.5 \\
\mathrm{C} 2=.12, \mathrm{w}=0.9\end{array}$ \\
\hline & ITAE & $\begin{array}{c}\mathrm{N}=2 \\
, \mathrm{n}=3, \mathrm{C} 1=\mathrm{C} 2=0.15 \\
, \mathrm{w}=0.9\end{array}$ \\
\hline
\end{tabular}

